Wenn diese Versuche denn auch in der That im Blute verschiedenartig vergifteter Thiere Milchsäure nachweisen, so düften diese kleinen Mengen organischer Säure immerhin von mehr untergeordnetem Werthe sein. Die Hauptsache wird der Nachweis einer enormen Herabsetzung des Oxydationsprocesses bleiben. Die so starke Herabsetzung der Kohlensäurebildung spricht deutlich in diesem Sinne.

Die herabgesetzte Oxydationskraft des Organismus aber wird sich auch auf andere Weise geltend machen, indem andere leicht verbrennbare Substanzen unter toxischen Einflüssen nicht mehr verbrennen - so verbrennt Benzol nicht mehr zu Phenol - und in gleicher Weise wird die in den verschiedensten Geweben immer wieder gebildete Milchsäure nicht mehr vollständig zu Kohlensäure und Wasser oxydirt und wird sich dem entsprechend im Blute und in den Geweben anhäufen müssen.

\title{
Aus einem Schreiben an den Herausgeber, betreffend die willkürliche Acceleration der Herzschläge.
}

\author{
Von
}

\section{J. H. Tarchamoff}

in St. Peterburg.

„Es war mir sehr angenehm zu erfahren, dass meine Arbeit iiber die willkiurliche Acceleration des Herzens beim Menschen Sie lebhaft interessirt hat. Diese eigenthümliche Fähigkeit ist in der That merkwürdig; aber ungliucklicherweise ist sie für die mit dieser begabten Personen sehr gefährlich, wie ich mich leider bei Hrn. Dr. Schlesinger überzengen musste. Er konnte ja willkürlich die Schlagzahl verdoppeln. Jetzt aber leidet er an so heftigem Herzklopfen, dass er nicht mehr ruhig schlafen kann. Da ich fürchte, dass die von mir mit Dr. S. angestellten Versuche eine Ursache dieses üblen Effectes sein könnten, möchte ich andere Forscher bitten, bei etwaigen Wiederholungen meiner Erfahrungen doch die äusserste Vorsicht anzuwenden." 